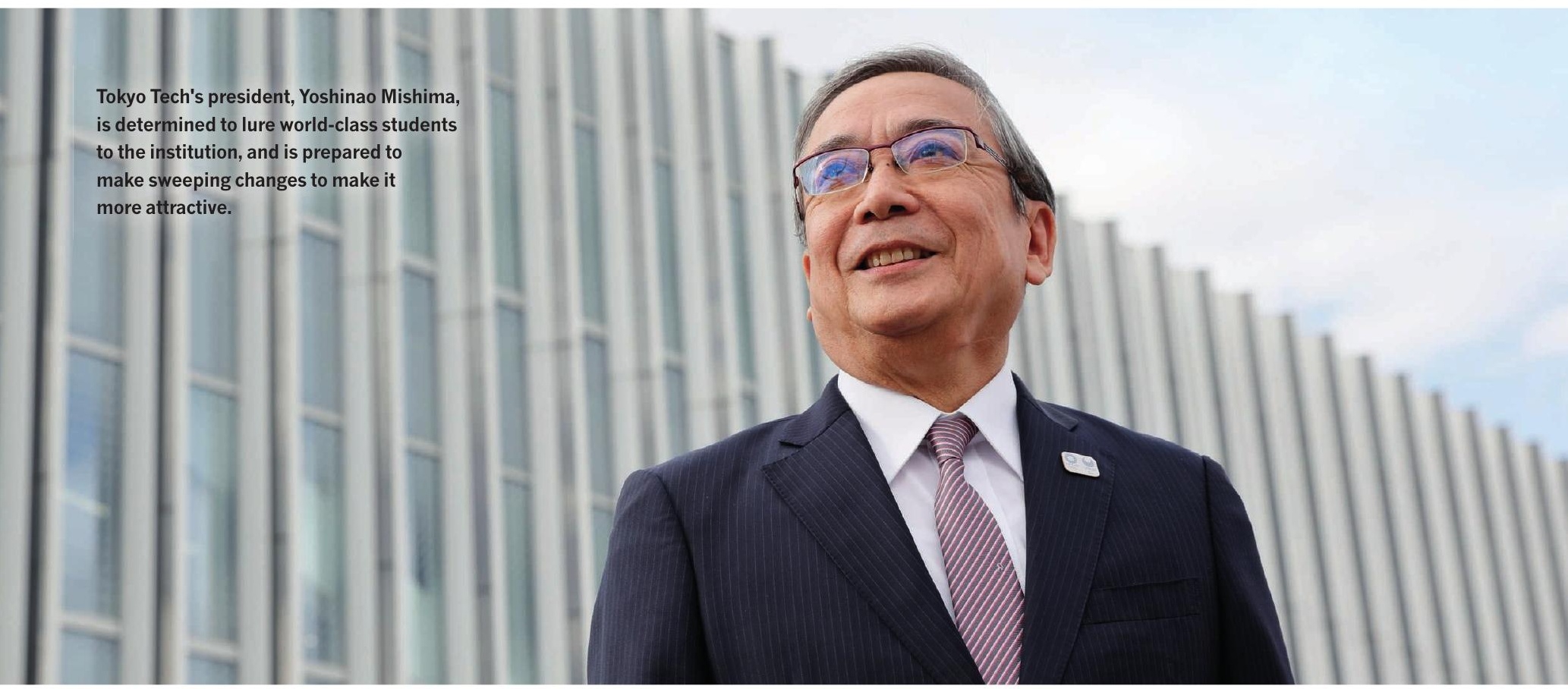

\title{
RESISTANCE TO REFORM
}

Efforts to improve Japan's scientific status include top-down institutional change, but tradition is hard to break.

\section{BY ICHIKO FUYUNO}

$\mathrm{I}$ n April 2016, Tokyo Tech's president, Yoshinao Mishima, made the unprecedented move of appointing department heads himself. For 137 years, positions at the Tokyo Institute of Technology had been decided by a faculty vote and a routine rotation based on seniority. Mishima's actions rattled the administration, but they weren't arbitrary. Revised laws governing national universities gave presidents greater discretion. The aim is to shake up the slow, consensus-based decision-making of Japanese university management, and to allow swift reform to the way universities are run.

Changing the culture of universities is central to Japan's efforts to arrest the deterioration in its research performance. Last year alarm bells rang over a $19.6 \%$ fall in its high-quality scientific output, the sharpest fall among the 10 leading research nations, as measured by the Nature Index over five years to 2016. There was a further $3.7 \%$ decline in 2017.

It is difficult to recalibrate the research ecosystem, and it will take time, as the situation at Tokyo Tech illustrates. Mishima is an exception: many leaders at large universities are slow to take advantage of the governance reforms.

In addition to appointing directors, Mishima also removed the final say on recruiting new researchers from faculty councils, and put in place a human resources committee with the president at its helm. "We have to make the university more attractive to lure the world's topclass students," says Mishima, who wants Tokyo Tech to join the ranks of the best engineering colleges globally by 2030 .

It's a tall order. The institution currently ranks at 65th for engineering and technology in the Times Higher Education's World University Rankings 2018. In the Nature Index, it ranked 79th globally for its total contribution to paper authorship in 2016.

But on other measures that matter for Mishima, Tokyo Tech stands out. The university ranks 9th among Japanese academic institutions above big names such as Keio, Tohoku and Kyushu, when its contribution to the index over the past six years is considered as a proportion of its total natural sciences output in the Scopus database.

\section{STAGNATED PERFORMANCE}

Japan holds on to 5 th place for output in the Nature Index after the United States, China, Germany and the United Kingdom. However, on one measure of efficiency - high-quality science article output per R\&D dollar, measured by the share of authorship in the index against gross spending on research and development — it falls to 30 th place among the 42 economies for which OECD R\&D spending data are available.

Universities are under pressure from the Ministry of Education, Sports, Culture, Science and Technology (MEXT) to improve management efficiency.

"Most universities fund researchers according to distribution rules with little flexibility, and do not evaluate their management strategies," says Atsushi Sunami, a science-policy expert at the National Graduate Institute for Policy Studies. $\mathrm{He}$ contends the biggest problems in national universities are inflexibility and the lack of agility in research and human resources management.

The management reform initiatives have yet to demonstrate any effect on national research outcomes. Some reforms have been met with stubborn resistance and adherence to tradition.

"They don't explicitly oppose me, but they are slow to take action," says Seiichi Matsuo, president of Nagoya University, describing faculty members' responses to his efforts to strengthen leadership. Nagoya University ranks 11th among Japanese academic institutions when normalizing its contribution to high-quality research against its total output in the natural sciences.

Yuko Ito, a policy expert at the Japan Science and Technology Agency (JST), says the extent of governance reforms varies by university. Until about five years ago, she heard professors 
calling for a return to the old system. But she says a shared sense of crisis is changing attitudes.

National university reforms began in 2004, when MEXT gave university management greater autonomy to build their competitiveness. Public research institutes underwent a similar change beginning in 2001.

In 2010, the state redoubled efforts to overhaul the university governance system and make them more competitive globally. MEXT directed national universities to accelerate organizational reforms such as increasing the use of English, introducing flexible human resources and payroll systems, and building strong presidential leadership.

Mishima, for example, integrated undergraduate and graduate schools into six schools and 19 departments. He set up an international advisory board, and formed councils to smoothly implement reforms.

Mishima plans to raise the proportion of graduate school lectures given in English from $31 \%$ in 2014 to almost $100 \%$ by 2021 . This change, he says, "will not only help attract more excellent overseas students, but allow Japanese students to get used to communicating in English before building a global career."

But many disagree with the approach, arguing that poor English among some teachers and students could affect the quality of education. "Why can't we use Japanese," asks a researcher at Tokyo Tech who requested anonymity. $\mathrm{He}$ points out that in many countries, such as Germany and France, courses are taught in the native language.

Evaluation has also been overhauled. In 2016, MEXT made a tenth of the total management expenses grants competitive. National universities had to classify themselves into one of three groups: serving the local economy, contributing to global research, or a unique teaching focus. Dozens of numerical key performance indicators are used to assess their strengths in each group; funding is commensurate.

Some university leaders question the value of meeting the targets given the relatively small amounts on offer. Tokyo Tech, for example, received the highest possible score on its evaluation, yet the increase in its management

\section{SCIENCE SPENDING}

Japan spent $3.29 \%$ of its GDP on research and development in 2015. This was a lower proportion than South Korea, but higher than the United States and China.
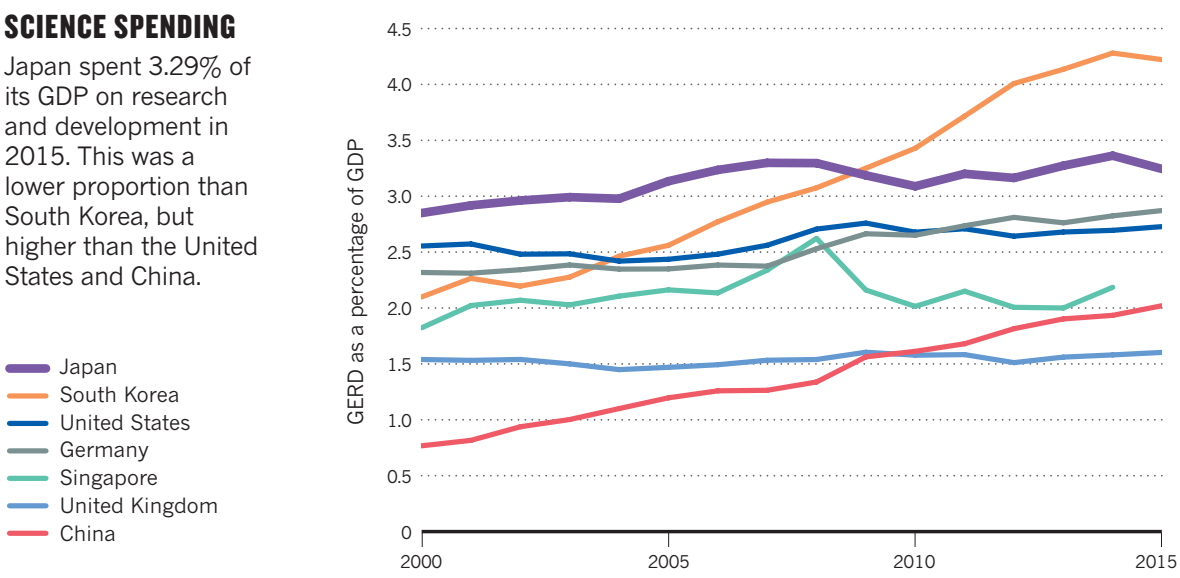

expense grants for 2017 was a mere $0.1 \%$. Some believe the intensification of evaluations with their heavy burden of paperwork is becoming counter-productive. Ito says the new system is diverting energy from research. "The government's evaluation is getting more severe in many ways. Universities look worn out from being evaluated."

\section{MORE WITH LESS?}

Changes have coincided with a period of austerity. Following rapid increases in the 1990s, the pace of growth in R\&D spending has stalled since 2001, due to social welfare costs during 20 years of economic stagnation.

Some blame a lack of money to employ adequate staff, more than management inefficiencies, for the decline in research quality.

Many universities have stopped hiring staff, replaced tenure positions with contract-based At the top research universities, nearly $40 \%$ of researchers were employed on contracts in 2013 , up from $27 \%$ in 2007 , according to NISTEP.

Funding cuts have affected smaller, regional universities more severely, as they struggle to earn external funding compared with prestigious universities such as The University of Tokyo.

Kouichi Okunishi is a physicist investigating condensed-matter theory at Niigata University, and part of a group established in 2015 to share concerns about the university's decision-making system. He is among those who say the lack of people is more debilitating than the lack of money for research.

In early 2016, when the university's management suspended hiring for two years, the group collected 300 signatures on a petition. But the hiring freeze was put in place anyway, he says. As a result, about 20 tenure positions have been lost shi says. Meanwhile, student numbers remain the same and faculty need to spend more time teaching undergraduate students and less on research.

Toshio Suda, director of the International Research Center for Medical Sciences positions and cut basic research spending. from the science, agriculture and engineering faculties due to staff members retiring, Okuni-

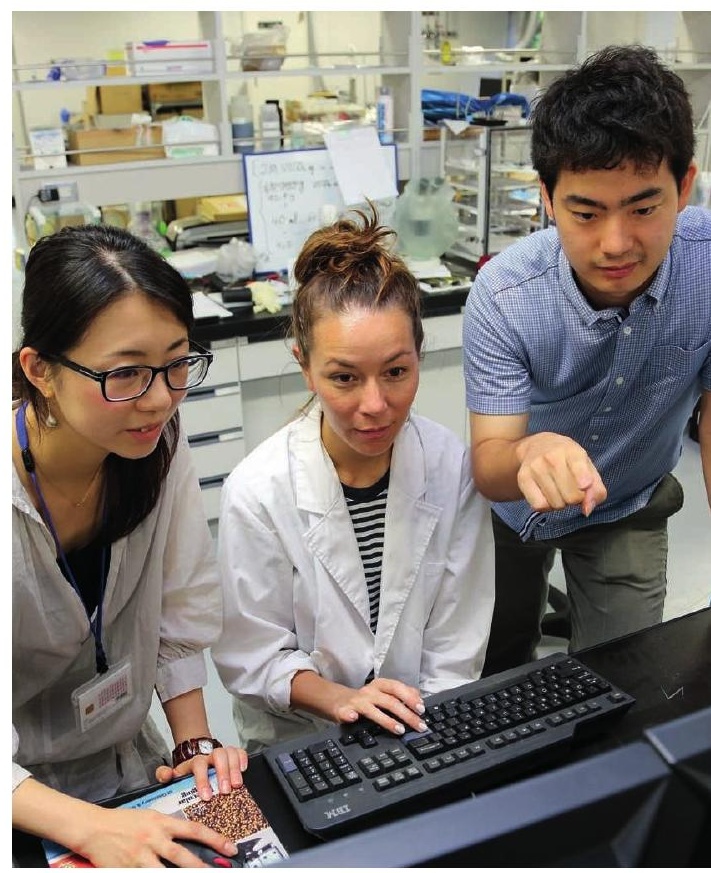

Researchers at Tokyo Tech.

(IRCMS), launched in 2015 at Kumamoto University, says recruitment is his biggest challenge. Although some $40 \%$ of IRCMS researchers are from other countries, Suda says it is very difficult to hire principal investigators from abroad, partly because there is little money for relocation. Instead, Suda is seeking to attract talented overseas postdocs and runs research intern programmes for students within Asia.

\section{TRYING TIMES}

The government has set a target of raising R\&D investment from $0.65 \%$ to $1 \%$ of GDP by 2020 . That translates to an additional 900 billion yen (US $\$ 8$ billion) over the next three years. The 2018 science and technology budget delivered a sharp increase of 250.4 billion yen in new money. A change in accounting method put a further 80.5 billion yen on the bottom line, bringing the total increase to $7 \%$.

Analysts welcomed the new money, saying it put the government on track to meet the 2020 target. Three-quarters of it came from ministries agreeing to invest in new technologies and automation to improve the productivity of infrastructure and services.

But no increase was approved for universities, despite a request for a $4 \%$ rise of 1.14 trillion yen, says Toshinori Sano, deputy director of the National University Corporation Support Division at MEXT. Meanwhile the number of students on financial aid that universities have to support using their management expenses increased by a few thousand.

"Japanese science is still competitive," says Guojun Sheng, an embryologist who joined IRCMS in Kumamoto in 2015. "But, now is the time to improve the efficiency and make the environment more attractive." 